\title{
DEFORMATION MONITORING OF HIGH-LATITUDE PERMAFROST REGION OF NORTHEASTERN CHINA WITH TIME SERIES INSAR TECHNIQUE
}

\author{
T. Qu ${ }^{1,2}, \mathrm{Q} . \mathrm{Xu}^{2}$, W. Shan ${ }^{3, *}, \mathrm{Z} \mathrm{Li}^{4}, \mathrm{M} . \mathrm{Shan}^{5}, \mathrm{~K} . \mathrm{Dai}^{2}$ \\ ${ }^{1}$ College of Engineering, Peking University, 100871 Beijing, China - tengteng.qu@pku.edu.cn \\ ${ }^{2}$ State Key Laboratory of Geohazard Prevention and Geoenvironment Protection, Chengdu University of Technology, Chengdu \\ 610059, China - (xq, daikeren17) @cdut.edu.cn \\ ${ }^{3}$ Institute of Cold Regions Science and Engineering, Northeast Forestry University, Harbin, China - shanwei456@163.com \\ ${ }^{4}$ COMET, School of Engineering, Newcastle University, Newcastle Upon Tyne NE1 7RU, UK - zhenhong.li@newcastle.ac.uk \\ ${ }^{5}$ Department of Earth Sciences, University of Florence, Firenze, Italy - shanmonan@yeah.net
}

Commission III, WG III/9

KEY WORDS: High-latitude Permafrost, Time Series InSAR, Deformation Monitoring, Sentinel-1, Island-like Permafrost

\begin{abstract}
:
Permafrost distributed in northeast China is the only high-altitude permafrost in China. The deformation monitoring over this permafrost region is of great importance to local climate change and ecological environments. This study focuses on the deformation monitoring of high-latitude permafrost in northeast China with time series InSAR technique. The spatial distribution characteristics, the annual deformation rates and the temporal deformation evolutions of permafrost could be retrieved from multi-temporal InSAR processing with Sentinel-1 TOPS datasets. This work concludes that time series InSAR technique could help to retrieve a comprehensive and reliable permafrost deformation, while a long time-series of displacements facilitated to better understand permafrost kinematics.
\end{abstract}

\section{INTRODUCTION}

As an important part of the earth's cryosphere system, permafrost is recognized as a key factor in land surface process of cold regions (Jorgenson et al., 2001). Permafrost, widely distributed in the Greater and Lesser Khingan Mountain located in northeastern China and the Baikal region in Russia, is recognized as the "Khingan-Baikal type" which is totally distinct from polar and high-altitude permafrost regions (Shan, Hu et al. 2015). This is China's solo high-latitude permafrost region and is also China's second largest permafrost region (Guo et al., 1981; Sun et al., 2007; Ran et al., 2012).

In recent decades, because of global warming, precipitation and other factors related to climate change, the southern boundary of China's northeast high-latitude permafrost region gradually moved northward due to accelerated permafrost degradation (Wang et al., 2014). The presence, moisture, temperature, distribution, and state of permafrost could be affected by many factors and demonstrate distinct spatiotemporal variations. Hence, long-term monitoring of surface deformation over frozen soil regions and exploitation of their spatial temporal characteristics are of great importance to local and global climate change, ecological environments, and cold region geo-hazard prevention and mitigation (Zhao et al., 2016).

The differential interferometric synthetic aperture radar technique (D-InSAR) has the advantage of high spatial resolution, large simultaneous observation area, and competitive accuracy, without geographical or man-made restrictions, thus could realize the macro dynamic monitoring of the surface deformations relating to the freezing and thawing process of permafrost.

As an important space mission of the Europe Space Agency in the Copernicus Programme, Sentinel-1 was launched on 2014 and opened a new era for radar satellite observations. Sentinel-1 has the ability to retrieve data in a relatively short period covering a long-time span, which is an important guarantee for mining the slowly changing permafrost for a long period of time, and greatly solves the bottleneck and difficulty of accumulating radar images in permafrost deformation monitoring. The application of Sentinel-1 satellite data for the deformation monitoring of permafrost regions with long time series and short time intervals has broad application prospects.

Hence, this work concentrates on the application of time series InSAR technique for monitoring and characterizing the surface deformation of a representative high-latitude permafrost region in northeastern China from 2017 to 2018. The spatial deformation characteristics of permafrost could be retrieved from time series InSAR processing with Sentinel-1 TOPS datasets. Long deformation evolutions of permafrost displacements could also facilitate to better understand permafrost kinematics.

\footnotetext{
* Corresponding author
} 


\section{STUDY AREA OF PERMAFROST REGION}

The study area (Figure 1) is located in the northwest section of the Lesser Khingan Mountains traversed by the Bei'an to Heihe Expressway (Shan et al., 2015). The terrain here is undulating with occasional steep slopes and relatively dense vegetation. The geological conditions in this region are extremely unstable. The altitude of the entire region ranges from $210 \mathrm{~m}$ to $330 \mathrm{~m}$. Climate here is characterized by long, dry and cold winters and short, hot and humid summers.

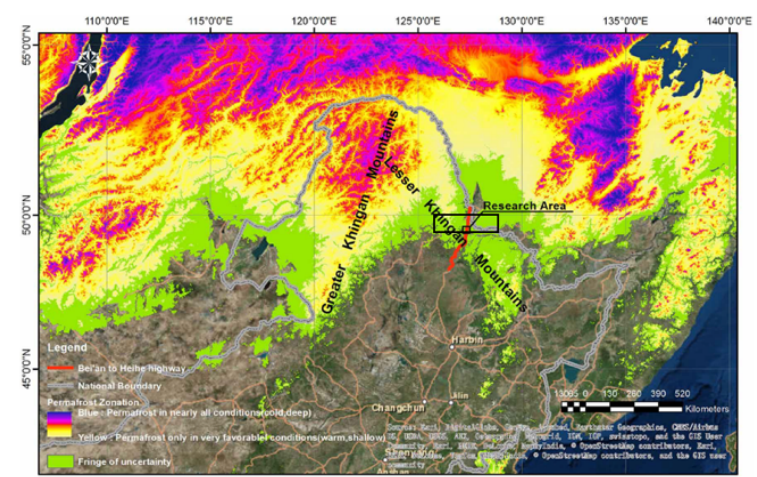

Figure 1. The overview of permafrost region in this study and high-latitude permafrost distribution in Northeast China with data from Zurich University, Switzerland

\section{TIME SERIES INSAR PROCESSING}

Previous research has demonstrated that the use of radar satellite like TerraSAR-X with shorter wavelength in this region would lead to serious de-correlation over permafrost (Shi, Liao et al. 2014). While Sentinel-1 interferograms over permafrost region of northeastern China in this study showed high correlations between acquisitions mainly because of its longer wavelength, short time intervals and precise orbital tubes. From the Sentinel-1 interferograms (Figure 2) of 12-day time intervals in January and February of 2017, the permafrost regions still showed high coherence despite of dense snow cover in winter. It should be noted that good correlations between radar acquisitions are the prerequisites to ensure the reliable time series InSAR processing.

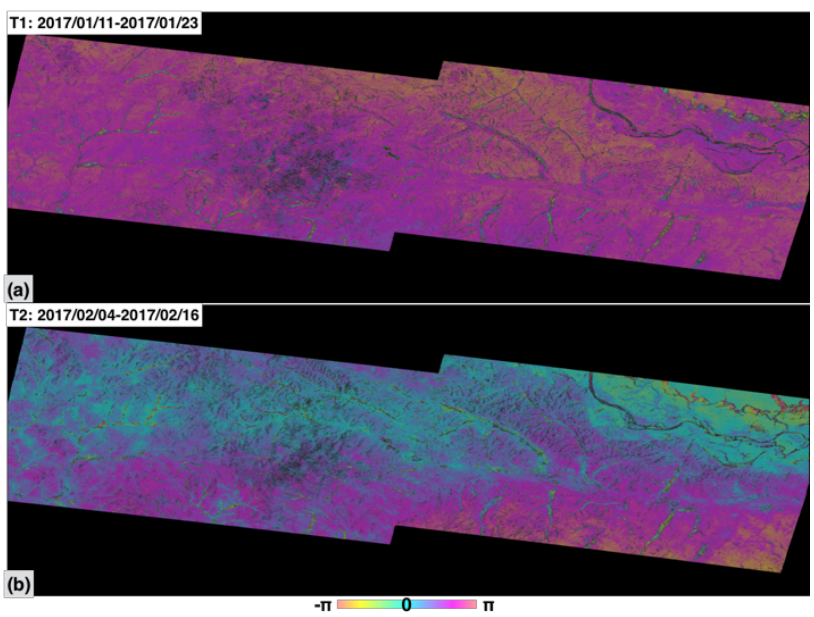

Figure 2. Sentinel-1 interferograms of high-latitude permafrost regions during time series InSAR processing
Time series InSAR technology has been developed for decades, which combines multiple radar images to reduce multiple decoherence situations. PS-InSAR (Permanent Scatter Interferometry) proposed by Ferretti (Ferretti et al., 2001) and SBAS (Small Baseline Subset) proposed by Berardino (Berardino et al., 2002) are the two most widely used time series InSAR methods.

In our study, time series InSAR processing is performed using a set of Sentinel-1 A/B scenes acquired from 2017 to 2018 to get the spatial distribution of surface displacements. As permafrost region has undulating terrains and abundant water vapor on valley slopes, which resulted in the severe problems of atmospheric disturbance in time series InSAR processing, TSInSAR-AEM method ( $\mathrm{Li}$ et al., 2009) proposed by Zhenhong $\mathrm{Li}$ is deployed with integration of atmospheric phase estimation, which accurately separated the atmospheric disturbance and improved the reliability of time series deformation results.

As the ground surface of frozen soil generally experiences seasonal uplift (frost heave) and subsidence (thaw settlement), a periodic deformation model is applied in TSInSAR-AEM processing, which not only helps to separate atmospheric artifacts from deformation signals more accurately, but also accelerates the convergence achieved during iterations.

\section{DEFORMATION CHARACTERISTICS OF PERMAFROST REGION}

\subsection{Spatial Distribution Characteristics of Permafrost}

Firstly, the spatial distribution characteristics of permafrost deformation could be analysed with representative interferometric pairs. Figure 3 shows the short-term deformation retrieved from DInSAR processing from $2018 / 02 / 11$ to $2018 / 02 / 23$. Although containing ineligible artifacts, the deformation results still show obvious spatial distribution characteristics of permafrost deformation.

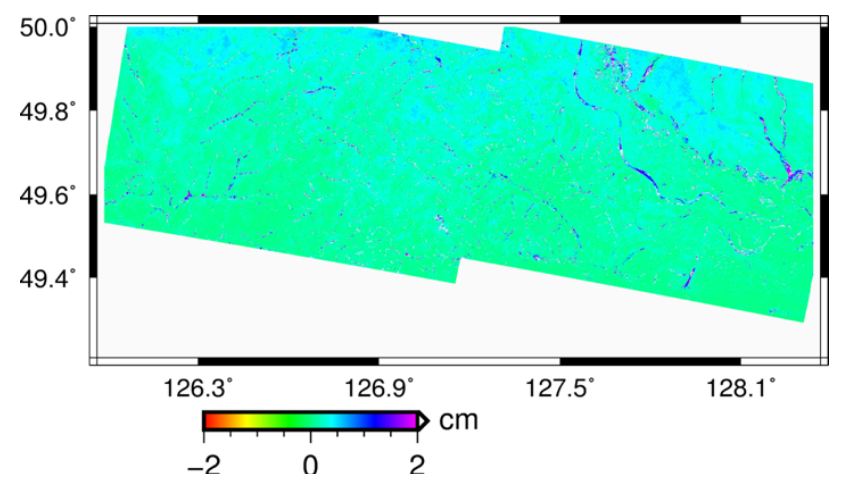

Figure 3. Short-term deformation retrieved from DInSAR processing of permafrost region from 2018/02/11 to $2018 / 02 / 23$ 
If we take a zoom-in view of the result in Figure 3, the permafrost shows discontinuous island-like distribution characteristics (Figure 4), which is consistent with previous studies (Jin et al., 2000; He et al., 2009; Wei et al., 2010).

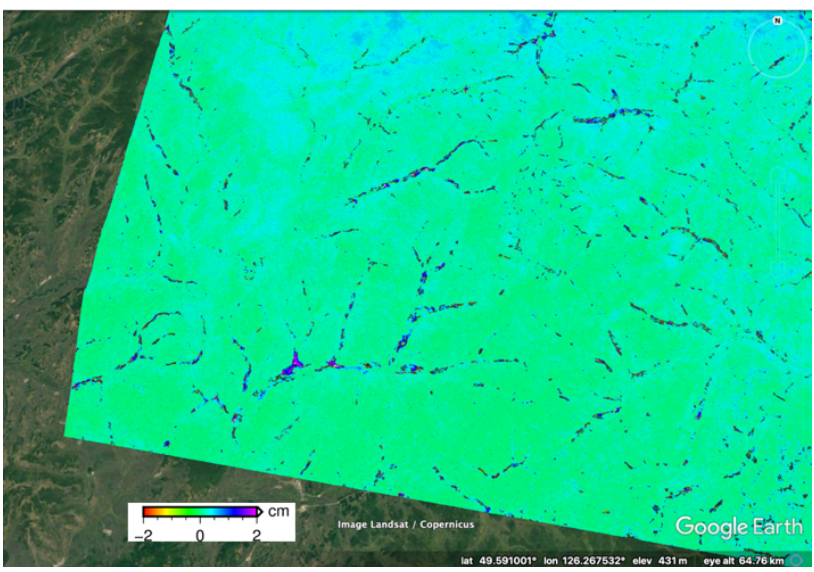

Figure 4. Spatial distribution characteristics of permafrost deformation

\subsection{Annual Displacement Rate of Permafrost}

Secondly, the anuual displacement rate map could be derived from time series InSAR processing (Figure 5). As a whole, the deformation rates of most of the permafrost region are no more than $20 \mathrm{~cm} / \mathrm{yr}$. However, there are still a few regions with an annual deformation of 40 centimeters.

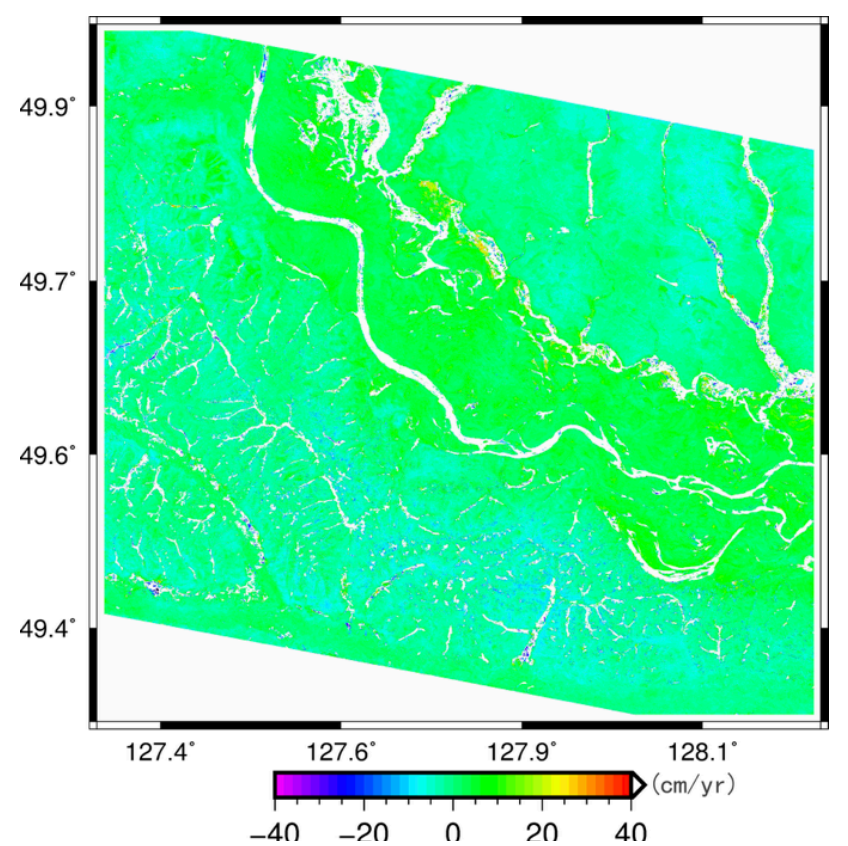

Figure 5. Deformation rate map derived from time series InSAR processing

\subsection{Temporal Deformation Evolution of Permafrost}

Figure 6 shows the time series deformation evolutions of permafrost region from the winter of 2017 to the spring of 2018. Time series results indicate that despite of cold winter season, the permafrost still deformed slowly with a significant discontinuous island-like distribution characteristic.
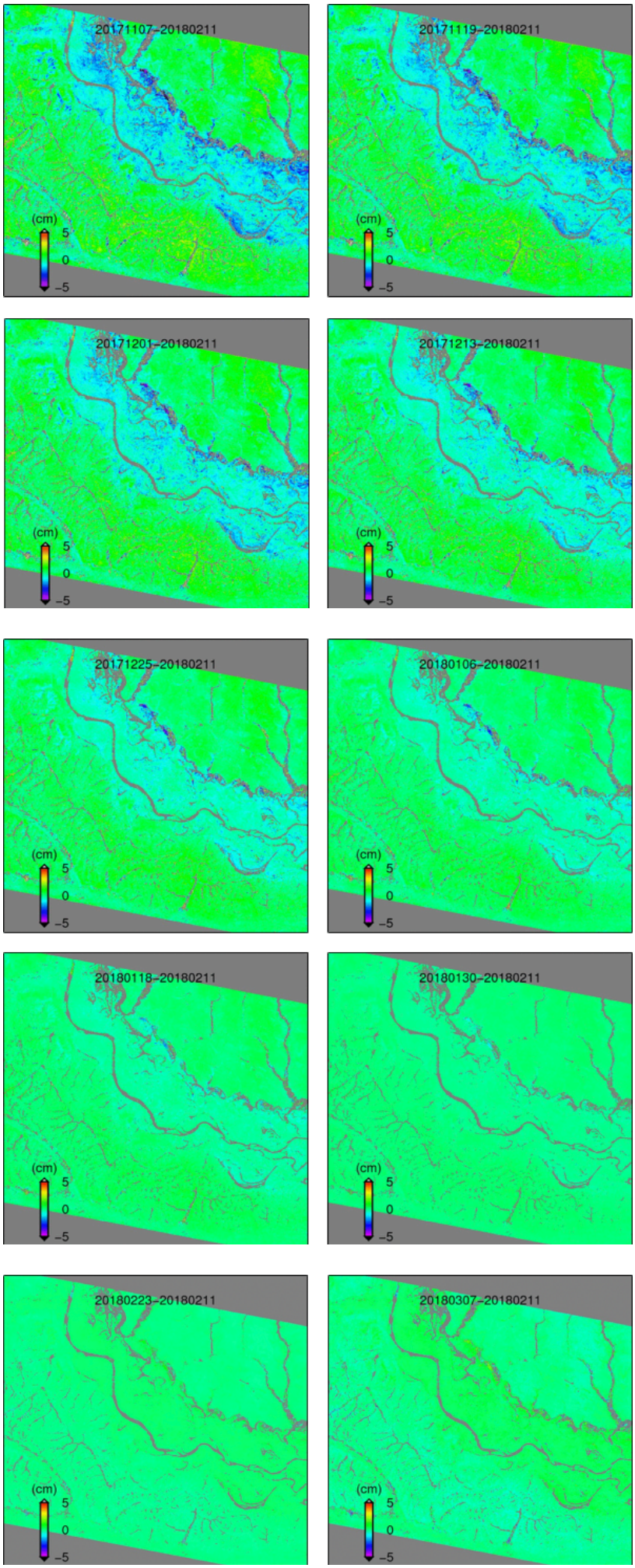

Figure 6. Time series evolution of permafrost region 


\section{CONCLUSIONS}

Deformation monitoring of high-latitude permafrost regions could be retrieved with time series InSAR processing using Sentinel-1 TOPS datasets. Longer time series deformation results would be able to cultivate the permafrost spatial temporal evolutions more comprehensively, showing that permafrost deformation changes with the season and demonstrates a notable annual cyclical characteristic and seasonal activity. Later studies would be carried out using measurement data from in situ sensors integrated with spaceborne radar remote sensing techniques, to cultivate the spatial temporal characteristics and degradation history of permafrost. Especially combined with measurements from pore water pressure installed in the boreholes of permafrost region, the corresponding relationship between InSAR acquired displacement variations and pore water pressure would illustrate that the seepage of water from thawing into frozen soil should be recognized as an important cause of permafrost movement.

This work concludes that spaceborne radar remote sensing applications could help to retrieve a comprehensive and reliable permafrost deformation, while a long time-series of displacements facilitated to better understand permafrost kinematics.

\section{ACKNOWLEDGEMENTS}

This work was supported by the Opening fund of State Key Laboratory of Geohazard Prevention and Geoenvironment Protection (Chengdu University of Technology) (SKLGP2019K022) and supported by State Key Laboratory of Geodesy and Earth's Dynamics (Institute of Geodesy and Geophysics, CAS) (SKLGED2019-5-1-E). The Sentinel-1 datasets are copyrighted by ESA. Some geocoded maps were generated by the General Mapping Tools (GMT).

\section{REFERENCES}

Berardino, P., Fornaro, G., Lanari, R., Sansosti, E., 2002. A new algorithm for surface deformation monitoring based on small baseline differential sar interferograms. IEEE Trans. Geosci. Remote Sens., 40, 2375-2383.

Ferretti, A., Prati, C., Rocca, F., 2001. Permanent scatterers in sar interferometry. IEEE Trans. Geosci. Remote Sens., 39, 820.

Guo, D. X., Wang, S. L., Lu, G., Dai, J. B., Li, E. Y., 1981. Regionalization of permafrost in the Da and XiaoXing'anling Mountains in northeastern China. J. Glaciol. Geocryol, 3(3), $1-9$.

He, R., Jin, H., Ma, W., Cheng, G., 2008. Recent changes of permafrost and cold regions environments in the northern part of Northeastern China. In AGU Fall Meeting Abstracts.

Jin, H. J., Li, S. X., Wang, S. L., 2000. Impacts of climatic change on permafrost and cold regions environments in China. ACTA GEOGRAPHICA SINICA-CHINESE EDITION-, 55(2), 173-181.

Jorgenson, M.T., Racine, C.H., Walters, J.C., Osterkamp, T.E., 2001. Permafrost degradation and ecological changes associated with a warmingclimate in central alaska. Clim. Chang, 48, 551-579.

Li, Z., Fielding, E. J., \& Cross, P., 2009. Integration of InSAR time-series analysis and water-vapor correction for mapping postseismic motion after the 2003 Bam (Iran) earthquake. IEEE Transactions on Geoscience and Remote Sensing, 47(9), 3220-3230.

Ran, Y.H., Xin, L., Cheng, G.D., Zhang, T.J., Wu, Q.B., Jin, H.J.; Rui, J, 2012. Distribution of permafrost in China: An overview of existing permafrost maps. Permafr. Periglac. Process., 23, 322-333.

Shan, W., Hu, Z., Guo, Y., Zhang, C., Wang, C., Jiang, H., Xiao, J., 2015. The impact of climate change on landslides in southeastern of high-latitude permafrost regions of China. Frontiers in Earth Science, 3, 7.

Shan, W., Hu, Z., Jiang, H., Guo, Y., Wang, C., 2015. Environmental and Engineering Geology of the Bei'an to Heihe Expressway in China with a Focus on Climate Change. In Engineering Geology for Society and Territory-Volume 1(pp. 271-277). Springer, Cham.

Shi, X., Liao, M., Wang, T., Zhang, L., Shan, W., Wang, C., 2014. Expressway deformation mapping using high-resolution TerraSAR-X images. Remote sensing letters, 5(2), 194-203.

Sun, G., Yu, S., Wang, H., 2007. Causes, south borderline and subareas of permafrost in Da Hinggan mountains and Xiao Hinggan Mountains. Scientia geographica sinica, 27(1), 68.

Wang, C., Shan, W., Guo, Y., Hu, Z., Jiang, H., 2014. Permafrost Distribution Study Based on Landsat ETM+ Imagery of the Northwest Section of the Lesser Khingan Range, China. In Landslide Science for a Safer Geoenvironment (pp. 529-534). Springer, Cham.

Wei, Z., Jin, H., Zhang, J., Yu, S., Han, X., Ji, Y., Chang, X., 2011. Prediction of permafrost changes in Northeastern China under a changing climate. Science China Earth Sciences, 54(6), 924-935.

Zhao, R., Li, Z. W., Feng, G. C., Wang, Q. J., Hu, J., 2016. Monitoring surface deformation over permafrost with an improved SBAS-InSAR algorithm: With emphasis on climatic factors modeling. Remote Sensing of Environment, 184, 276287. 